\title{
Differences in the Flexion and Extension Phases during Kneeling Investigated by Kinematic and Contact Point Analyses: A Cross-sectional Study
}

\section{Yusuke Nakazoe}

Nagasaki University: Nagasaki Daigaku

Akihiko Yonekura ( $\nabla$ a-yone@umin.ac.jp)

Nagasaki University: Nagasaki Daigaku

Hiroyuki Takita

Nagasaki University: Nagasaki Daigaku

Takeshi Miyaji

Nagasaki University: Nagasaki Daigaku

Narihiro Okazaki

Nagasaki University: Nagasaki Daigaku

Ko Chiba

Nagasaki University: Nagasaki Daigaku

Kenichi Kidera

Nagasaki University: Nagasaki Daigaku

Takashi Miyamoto

Nagasaki University: Nagasaki Daigaku

Masato Tomita

Nagasaki University: Nagasaki Daigaku

Kazuyoshi Gamada

Hiroshima International University: Hiroshima Kokusai Daigaku

Makoto Osaki

Nagasaki University: Nagasaki Daigaku

\section{Research article}

Keywords: kneeling, kinematics, deep knee flexion, healthy knee, 2D/3D registration technique

Posted Date: September 17th, 2021

DOl: https://doi.org/10.21203/rs.3.rs-895656/v1

License: (a) (i) This work is licensed under a Creative Commons Attribution 4.0 International License. Read Full License 
Version of Record: A version of this preprint was published at Journal of Orthopaedic Surgery and Research on March 28th, 2022. See the published version at https://doi.org/10.1186/s13018-022-03080-x. 


\section{Abstract}

Background: Kneeling is necessary for certain religious and ceremonial occasions, crouching work, and gardening, which many people take part in worldwide. However, there have been few reports regarding kneeling activities. The purpose of this study was to clarify the kinematics of kneeling.

Methods: The subjects were 15 healthy young males. Kneeling activity was analysed within a knee flexion angle from $100^{\circ}$ to maximum flexion (maxflex, mean $\pm \mathrm{SD}=161.3 \pm 3.2^{\circ}$ ). The kinematic and contact point (CP) analyses were performed using a 2D/3D registration method, in which a 3D bone model created from computed tomography images was matched to knee lateral fluoroscopic images and analysed on a personal computer.

Results: In the kinematic analysis, the femur translated $37.5 \mathrm{~mm}$ posteriorly and rotated $19.8^{\circ}$ externally relative to the tibia during the knee flexion phase. During the knee extension phase, the femur translated $36.4 \mathrm{~mm}$ anteriorly, which was almost the same amount as in the knee flexion phase. However, the femur rotated only $7.4^{\circ}$ internally during the knee extension phase. In the CP analysis, the amount of anterior translation of the $\mathrm{CP}$ in the knee extension phase was greater in the medial $\mathrm{CP}$ and smaller in the lateral $\mathrm{CP}$ than that of posterior translation in the knee flexion phase.

Conclusions: In kneeling, there was a difference in the rotational kinematics between the flexion phase and the extension phase. The kinematic difference between the flexion and extension phases may have some effect on the meniscus and articular cartilage.

\section{Background}

Kneeling is a movement that flexes the knee joint deeply with the tibial tubercle on the ground. It is one of the deep knee flexion activities, like squatting or lunging. Kneeling is required for religious and ceremonial occasions in Asia. The posture that holds the deep knee flexion position is called "Seiza" in Japan. Kneeling is also often done in activities such as crouching work and gardening. The relationship between the onset of knee joint diseases (such as knee osteoarthritis (OA) and meniscal injury) and the occupations requiring frequent deep knee flexion has been reported in recent years [1-4]. During kneeling activity, a series of knee joint kinematics of flexion and extension may be repeated many times, which may have an effect on intraarticular components such as the menisci and cartilage. Therefore, it is important to clarify the characteristic kinematics of kneeling.

Deep knee flexion analysis has been reported since the late 1990s in static and cadaver knee studies [5-9]. There are many reports of dynamic studies of knee kinematics after total knee arthroplasty, and several of deep knee flexion and kneeling situations have already been reported [10-15]. Subsequently, there have appeared some reports of the kinematics of squat and lunge activities in dynamic studies of healthy knees [16-19]. However, there have been only a few reports of kneeling of healthy knees [20-23]. According to these reports, the femur translates posteriorly and rotates externally during deep knee flexion. On the other hand, contact point (CP) analysis has been used as a method for analysing the movements of the medial and lateral femorotibial CPs separately $[18,20,24]$. It has been reported that there were significant 
differences in the lateral CP and no differences in the medial CP in the flexion phase of kneeling [20]. However, no reports have investigated the knee extension phase. Kneeling is different from squatting and lunging in that the femoral condyles move on the tibial plateau that is almost perpendicular to the ground. A gravitational force of the femur that slides down on the tibial plateau always affects kneeling. The anterior translation of the femur on the tibial plateau with this gravitational force in the knee extension phase may be different from the posterior translation of the femur against this gravitational force in the knee flexion phase.

A previous study reported that there is no difference in the kinematics of kneeling activity between the extension phase and the flexion phase [22]. However, the subjects in that study varied in sex and were relatively old. We planned to clarify the distinctive kinematics of kneeling by analysing only knees in young males with no apparent trauma history or OA. In addition, we planned to investigate the movement of medial and lateral CPs not only in the flexion phase, but also in the extension phase. To clarify the kinematics and CPs that have not been elucidated in the previous studies of kneeling activity, we hypothesized the following:

1. The kinematics of femoral translation and/or rotation in the extension phase are different from those in the flexion phase.

2. The movements of the medial and lateral CPs are different between the flexion phase and the extension phase.

\section{Methods}

\section{Subjects}

This study was conducted as part of a cross-sectional study. According to the protocol approved by the hospital ethics committee (approval number: 08070298-2), subjects were selected from hospital patients. The inclusion criteria were: 1 ) males over 20 years of age; 2 ) those with no history of trauma or surgery on the subject knee; 3 ) those with full knee extension and knee flexion $>145^{\circ}$; 4 ) X-ray examination showing no $\mathrm{OA}$; and 5) those who gave informed consent. Females were excluded from the present study to avoid radiation exposure because of the possibility of pregnancy. Ultimately, 15 males (15 knees) with an average age of $28.2 \pm 6.9$ years, an average height of $169.9 \pm 6.5 \mathrm{~cm}$, an average weight of $70.4 \pm 11.9 \mathrm{~kg}$, and an average body mass index (BMI) of $25.3 \pm 5.1 \mathrm{~kg} / \mathrm{m}^{2}$ were included.

\section{Kneeling action and lateral fluoroscopic imaging}

As for the starting posture, the frontal part of the lower leg was placed on a radiolucent box (Fig. 1a). The starting knee posture was set to a knee flexion angle of $90^{\circ}$ measured by the goniometer. The hip joint was in the intermediate flexion/extension position, and the ankle was not fixed and was able to move freely. The contralateral leg was placed backwards so that it did not overlap the examined knee on the fluoroscopic image. The subjects were tested while holding onto a handrail for safety and in order to apply half of their 
body weight to the examined knee. To minimize the exposure dose, the subjects wore a radiation protector on the hips during fluoroscopy.

The subject was instructed to perform the reciprocating movement over about 5 seconds so as not to sway from side to side during image capture. The subject practiced several times until smooth kneeling action was achieved. First, the images of the flexion phase were captured. The subject then started to kneel down from a knee flexion angle of $90^{\circ}$ toward the maximum flexed knee position until his buttock touched the heel (Fig. 1b). Then, a series of actions returning from the maximum flexed knee position to a knee flexion angle of $90^{\circ}$ were performed as the extension phase (returned to the same posture as Fig. 1a). The actual kneeling motion took 6-8 seconds, similar to previous reports [22].

The fluoroscope used in this study was a square, 17-inch, flat panel screen (C-vision Safire, Shimadzu Corp., Kyoto, Japan). The imaging frame rate was $5 \mathrm{~Hz}$, and the image size was $1024 \times 1024$ pixels. A series of actions were recorded as the kinematic data. Static images were extracted from the kinematic data. The flexion phase and the extension phase were analysed separately.

\section{D bone model creation and coordinate system embedding}

The 3D bone models of the femur and tibia were created from CT images (SOMATOM Definition, Siemens AG, Erlangen, Germany). In all cases, CT scans were performed with 0.5-mm-thick slices, approximately 150 $\mathrm{mm}$ proximal and distal from the knee joint line. 3D-Doctor (Able Software Corp., Lexington, MA, USA) was used to surround the exterior cortical bone edges of each axial image one by one. 3D bone models were created based on these images.

The bone coordinate system was set using 3D-Aligner (GLAB Corp., Higashi-Hiroshima, Japan). A coordinate system was incorporated into each bone model of the femur and tibia (Fig. 2). The femoral and tibial coordinate system was based on the definition of Grood and Suntay [25]. The femoral reference point was located at the most distal point on the mid-plane of the intercondylar notch. The Z-axis pointed proximally and passed through the centre of the femoral head. The $X$-axis passed the femoral reference point and was parallel to the line connecting the most posterior points of the two femoral condyles. The Yaxis was mutually perpendicular to the $X$ - and $Z$-axes. The tibial reference point was located at the centre of the apex of the medial-lateral intercondylar ridge and was the lowest point on the bone surface. The Z-axis pointed proximally and passed from the centre of the ankle joint and through the tibial reference point. The $X$-axis passed the tibial reference point and was parallel to the line connecting the midpoints of the medial and lateral tibial condyles. The $\mathrm{Y}$-axis was mutually perpendicular to the $\mathrm{X}$ - and Z-axes.

\section{Kinematic and contact point analyses}

Knee joint kinematics and contact points were analysed by the 2D/3D registration method using X-ray lateral fluoroscopic images and CT images of the knee joint developed by Banks et al. [26]. Previous reports have shown that this method is accurate and has very few errors [27]. Moro-oka et al. reported that the 
accuracy of this technique was $0.53 \mathrm{~mm}$ for in-plane translation and $0.54^{\circ}$ for rotation [28]. Komistek et al. reported that accuracy was $0.45 \mathrm{~mm}$ for in-plane translation and $0.66^{\circ}$ for rotation [29]. We previously used this method to investigate squatting activity [30,31].

The 3D bone models embedded with the coordinate system were projected onto the distortion-corrected fluoroscopic images. The silhouettes of the bone models were iteratively adjusted to match the silhouettes of the bones on the fluoroscopic image with the custom Joint Track program (sourceforge.net/projects/jointtrack) (Fig. 3). Then, six degrees-of-freedom joint kinematics were computed using commercial software (3D JointManager, GLAB Corp.).

Kinematic analysis was assessed by the movement of the femur relative to the tibia. Both antero-posterior (AP) translation of the femoral reference point and internal-external (IE) rotation of the femoral $X$-axis on the tibial X-Y plane were measured. The B-spline curve approximation was selected, as in our previous reports, to reproduce the smooth movement of the knee joints [30,31]. The kinematics were analysed in $5^{\circ}$ increments of the knee flexion angle after B-spline curve approximation. In all data processing, only interpolation was performed; extrapolation was not performed.

In addition, $\mathrm{CP}$ analysis was performed. The contact area was analysed using the same commercial software (3DJointManager, GLAB Corp.) used in the kinematic analysis. The motions of medial and lateral femoral condyles have been evaluated by the medial and lateral CPs, respectively $[18,24]$. The bone surfaces of the femur and tibia are composed of a collection of polygons. The distance between polygons composed of the bone surfaces of the femur and tibia was calculated as the proximity distance. An area within a certain proximity distance was defined as the contact area. The minimum proximity distance at which the contact area appeared varied depending on the subject, with a minimum of $5.5 \mathrm{~mm}$ and a maximum of $7.0 \mathrm{~mm}$. The geometric centre, which is the centre of gravity of the contact area, was defined as the CP. The CP was represented by the coordinate position on the tibial X-Y plane. Each medial and lateral CP was digitized separately, and a series of movements of the CPs were evaluated for each knee flexion angle.

\section{X-ray exposure dose}

In the present study, the subjects' X-ray exposure doses were confirmed to be $22 \mathrm{mSv}$ with fluoroscopy and $8 \mathrm{mSv}$ with $\mathrm{CT}$. Only one cycle of kneeling action was allowed on fluoroscopic examination to minimize the exposure dose [34].

\section{Statistical analyses}

SPSS version 22 (SPSS Inc., Chicago, IL, USA) was used for statistical analysis. A paired $t$-test was used for comparison between the flexion phase and the extension phase with the knee flexion angle as the independent variable. $P<0.05$ was considered significant. 
The difference between the flexion phase and the extension phase at each flexion angle of each case was calculated. Using a mixed model for repeated measurements with the numerical value of the difference as the objective variable, whether there was an overall difference between the flexion phase and the extension phase was evaluated.

\section{Results}

\section{Kinematic analysis}

The femur translated posteriorly in the flexion phase and anteriorly in the extension phase relative to the tibia on the kinematic analysis (Fig. 4a). The average amount of femoral posterior translation during the knee flexion phase from $100^{\circ}$ to maximum flexion (maxflex, mean $\pm \mathrm{SD}=161.3 \pm 3.2^{\circ}$ ) was $37.5 \mathrm{~mm}$, and it was $-36.4 \mathrm{~mm}$ during the extension phase from maxflex to $100^{\circ}$ (Table 1). Comparing the femoral posterior translation for each knee flexion angle, there were significant differences between both phases from a knee flexion angle of $100^{\circ}$ to $120^{\circ}$. The estimated overall difference for femoral posterior translation between the flexion and extension phases was $0.48 \mathrm{~mm}$ ( $95 \%$ confidence interval $(\mathrm{Cl}) 0.08$ to $0.87 \mathrm{~mm}$ ).

The femur rotated externally with knee flexion and internally with knee extension relative to the tibia on the kinematic analysis (Fig. 4b). The average amount of femoral external rotation during the knee flexion phase from $100^{\circ}$ to maxflex was $19.8^{\circ}$, and it was $-7.4^{\circ}$ during the extension phase from maxflex to $100^{\circ}$ (Table 2). Comparing femoral external rotation for each knee flexion angle, there was a significant difference between both phases from a knee flexion angle of $100^{\circ}$ to $155^{\circ}$. The estimated overall difference for IE rotation between the flexion and extension phases was $-9.86^{\circ}\left(95 \% \mathrm{Cl}-13.75^{\circ}\right.$ to $\left.-5.97^{\circ}\right)$. That is, the amount of femoral AP translation was almost the same in the two phases, but the amount of femoral IE rotation was less in the extension phase than in the flexion phase on the kinematic analysis.

\section{Contact point analysis}

The medial CP translated $3.4 \mathrm{~mm}$ posteriorly with a knee flexion angle from $100^{\circ}$ to maxflex in the flexion phase: $3.8 \mathrm{~mm}$ anteriorly from $100^{\circ}$ to $140^{\circ}$, and $7.2 \mathrm{~mm}$ posteriorly from $140^{\circ}$ to maxflex (Fig. 5a, Table 3). In the extension phase, the medial CP translated $8.6 \mathrm{~mm}$ anteriorly with a knee flexion angle from maxflex to $100^{\circ}, 11.0 \mathrm{~mm}$ anteriorly from maxflex to $125^{\circ}$, and $2.4 \mathrm{~mm}$ posteriorly from $125^{\circ}$ to $100^{\circ}$. There was a significant difference between the two phases with a knee flexion angle from $100^{\circ}$ to $140^{\circ}$. The estimated overall difference for the medial CP translation between the flexion and extension phases was $-3.41 \mathrm{~mm}$ ( $95 \% \mathrm{Cl}-4.88$ to $-1.93 \mathrm{~mm}$ ). That is, the medial CP was located more anteriorly in the extension phase than in the flexion phase.

The lateral CP translated continuously $14.2 \mathrm{~mm}$ posteriorly with a knee flexion angle from $100^{\circ}$ to maxflex in the flexion phase (Fig. 5b, Table 4). Similarly, the lateral CP translated continuously $9.8 \mathrm{~mm}$ anteriorly with a knee flexion angle from maxflex to $100^{\circ}$ in the extension phase. There was a significant difference between the two phases with a knee flexion angle from $100^{\circ}$ to $155^{\circ}$. The estimated overall difference for 
the lateral CP translation between the flexion and extension phases was $2.92 \mathrm{~mm}(95 \% \mathrm{Cl} 1.82$ to 4.01 $\mathrm{mm}$ ). That is, the lateral CP was located more posteriorly in the extension phase than in the flexion phase.

\section{Discussion}

From the present results, in kneeling, posterior translation and external rotation of the femur relative to the tibia were observed with knee flexion, and anterior translation and internal rotation of the femur were observed with knee extension. The amount of rotation was smaller in the extension phase than in the flexion phase, which has not been reported previously. Furthermore, large anterior translation of the medial femoral condyle in the extension phase compared with in the flexion phase was observed, which is also a new finding.

The relationship between kneeling activity with meniscus injury and knee OA has been shown epidemiologically. In a cohort study, Jensen et al. reported that kneeling workers had an odds ratio of 2.82 ( $95 \% \mathrm{Cl} 1.25$ to 6.36 ) for medial meniscus injury, and workers repetitively kneeling for more than 30 years had an odds ratio of 4.82 ( $95 \% \mathrm{Cl} 1.38$ to 17.0$)$ for femorotibial OA, compared with non-kneeling workers [3]. On the other hand, Nagura et al. analysed the moment and force applied to the knee joint during squatting and kneeling using a motion capture system with a ground reaction force plate [32-34]. They reported that the contact pressure of the knee joint was very high in the deep knee flexion position. Nakagawa et al. observed the meniscus by open MRI at various knee flexion angles and reported that the medial meniscus was sandwiched between the femoral condyle and the posterior part of the tibial condyle at the maximum knee flexion position [8]. Furthermore, it was reported that the posterior horn of the medial meniscus had the least amount of movement, with a potential risk of meniscus damage $[35,36]$. In addition to these intraarticular states, the repetition of different rotational kinematics and CP translation in the flexion and the extension phases in activities of daily living and work might be involved in medial meniscus injury and development of OA.

There have been a few reports of kinematic analyses of kneeling. Regarding kneeling in the flexion phase, Moro-oka et al. reported that the femur rotated externally [20]. Kono et al. reported that the femur rotated $14.8^{\circ}$ externally with a knee flexion angle from $100^{\circ}$ to $150^{\circ}$ [21]. Scarvell et al. reported that the femur rotated $8^{\circ}$ externally and translated $36 \mathrm{~mm}$ posteriorly relative to the tibia with a knee flexion angle from $90^{\circ}$ to $150^{\circ}$ [22]. The present results showed that the femur rotated externally $19.8^{\circ}$ and translated posteriorly $37.5 \mathrm{~mm}$ with a knee flexion angle from $100^{\circ}$ to maxflex. Thus, the result of the kinematic analysis of kneeling activity in the flexion phase was in the same direction of IE rotation and AP translation of the femur as seen in previous reports. Different femoral and tibial coordinate systems could be one of the reasons for the variations in the amounts of IE rotation and AP translation among these reports.

To the best of our knowledge, only two reports have shown the kinematic data both in the flexion and in the extension phases in kneeling using the $2 \mathrm{D} / 3 \mathrm{D}$ registration method. Scarvell et al. analysed kneeling in both the flexion and extension phases, and they reported that kneeling required femoral posterior translation and external rotation [22]. Galvin et al. analysed kneeling in four 20-year age groups and reported that there was no relationship between aging and the inability to kneel, except in the over 80-year age group [23]. However, 
they did not mention the difference in the amount of rotation between the flexion phase and the extension phase. In the present results, the amount of rotation was smaller in the extension phase than in the flexion phase. The reason for this difference might be related to the age and sex distributions of the subjects. The present subjects were only males with an average age of 28.2 years, whereas the subjects in the study by Scarvell et al. were 13 males and 12 females with an average age of 62 years, and subjects in the study by Galvin et al. were 30 males and 36 females in various age groups. The difference between the flexion phase and the extension phase in the present study, which has not been reported previously, may be a result of the potential tolerance and flexibility of a healthy knee of a relatively young generation.

To the best of our knowledge, only two reports have analysed the translation of the medial and lateral femoral condyles individually in the flexion phase of kneeling using the $2 \mathrm{D} / 3 \mathrm{D}$ registration method. Morooka et al. reported that the medial CP translated $3 \mathrm{~mm}$ anteriorly, and the lateral CP translated $8 \mathrm{~mm}$ posteriorly with a knee flexion angle from $100^{\circ}$ to $150^{\circ}$ [20]. Kono et al. reported that the medial femoral epicondyle sulcus did not translate significantly, and the lateral femoral condyle translated $40.2 \%$ posteriorly relative to the AP length of the tibia with a knee flexion angle from $100^{\circ}$ to $150^{\circ}$ [21]. In the present study, the medial CP translated $3.4 \mathrm{~mm}$ posteriorly, and the lateral CP translated $14.2 \mathrm{~mm}$ posteriorly with a knee flexion angle from $100^{\circ}$ to maxflex. On the other hand, in the extension phase, the medial CP translated $8.6 \mathrm{~mm}$ anteriorly and the lateral CP translated $9.8 \mathrm{~mm}$ anteriorly with a knee flexion angle from maxflex to $100^{\circ}$. This discrepancy between the flexion and extension phases in the amount of AP translation of the CPs, which is a new finding, could affect the intra-articular components, such as the menisci and cartilage.

The following two points were considered to be the reasons for the kinematic difference between the flexion phase and the extension phase. The first point was the balance of muscle contraction within the hamstrings. Kwak et al. reported that the hamstrings are largely involved in knee joint stability [37]. MacWilliams et al. reported that hamstring co-contraction decreases tibial internal rotation during knee flexion under weight-bearing [38]. The hamstrings produce an efferent contraction during knee extension, and muscle contraction is expected to occur more strongly than during knee flexion. Therefore, the amount of rotation was likely reduced in the extension phase compared to the flexion phase, which may have led to this smaller rotation in the extension phase. Victor et al. stated that the contraction of the lateral hamstring was responsible for the rotation, particularly the decrease of tibial internal rotation [39]. From these facts, it was thought that the contraction of the lateral hamstring was greatly involved as the cause of the smaller rotation in the extension phase compared to the flexion phase. Second, the sliding-down force of the femur on the tibial plateau surface that was perpendicular to the floor might have affected the knee kinematics during the kneeling activity. At the time of flexion, the femur is already in the position closest to the floor in the starting posture, and deep flexion motion occurs from there. However, when extending, in addition to the anterior translation of the CPs, a force that slides inferiorly along the tibial plateau surface acting in the same direction is added. For these reasons, a phenomenon likely occurs in which the medial CP translates more anteriorly in the extension phase, as in the present results. Therefore, the amount of femoral rotation probably differed between the flexion phase and the extension phase in the present study due to the effects 
of these muscle actions and the force of the femur sliding inferiorly along the tibial plateau surface in the extension phase.

The CT-based CPs that were used may differ from the actual CPs, such as cartilage-to-cartilage and/or cartilage-to-meniscus CPs, since conditions of soft tissues such as cartilage and meniscus are not considered in the CT-based bone models. There are some reports of CP analysis using models that consider soft tissue conditions. First, by using MRI-based 3D surface models, it is possible to reflect the thickness of the femoral and tibial cartilages in the results [40]. A cartilage-to-cartilage CP analysis during walking, lunging, and stair climbing has been reported using MRI-based 3D surface models [41-43]. Moro-oka et al. reported that the kinematic analysis using CT-based models was more accurate than that using MRI-based models (0.3-T) in a direct comparison using lateral fluoroscopic images [28]. Although the CT-based and MRI-based models have not been directly compared, it has also been reported that highly accurate analysis is possible using 3.0-T MRI and two orthogonal fluoroscopic images [41, 44]. Second, dynamic MRI can analyse the kinematics and contact area of the knee joint without radiation exposure. In recent years, it has been reported that very accurate analysis has become possible using 3.0-T MRI [45]. Borotikar et al. reported that the cartilage contact area of the patellofemoral joint increased as the knee flexion angle increased from $0^{\circ}$ to $40^{\circ}$ using cine-PC MRI [46]. However, there are restrictions on conditions such as the narrow space and the knee flexion angle when taking images, and the motion analysis of kneeling activity may be difficult by dynamic MRI. Third, computer simulation has been developed with technological progress in recent years and is very useful for predicting knee kinematics after total knee arthroplasty and elucidating the kinematics of soft tissues such as the anterior cruciate ligament [47-49]. Wang et al. analysed the standing and kneeling postures using the finite element method and reported that kneeling could cause cartilage damage in the patellofemoral joint [50]. However, it is necessary to set various conditions such as load conditions, tissue characteristics of cartilage and ligaments, and muscle action for computer simulation, and it has been reported that the numerical values of these conditions greatly affect the results [51]. The development of MRI and computer simulation technology is greatly anticipated to elucidate the actual contact points and mechanical loads of cartilage and meniscus, while giving priority to safety, such as eliminating radiation exposure of participants.

Regarding the reliability of the CT-based CP analysis that was used, DeFrate et al. compared the CT-based CPs and the MRI-based cartilage-to-cartilage CPs [44]. They reported that the CT-based CPs and the MRIbased cartilage-to-cartilage CPs did not match at a knee flexion angle of $0^{\circ}$, where the cartilage is relatively thin. However, they also reported that these two CPs matched at knee flexion angles of $30^{\circ}, 60^{\circ}$, and $90^{\circ}$. To the best of our knowledge, no report has compared the CT-based and MRI-based CPs at knee flexion angles greater than $90^{\circ}$. On the other hand, Pinskerova et al. analysed MRI images taken at each knee flexion angle in a cadaveric knee study, and they reported that the medial femoral condyle began to ride up onto the posterior horn of the medial meniscus at a knee flexion angle of $140^{\circ}$ [9]. It is considered that cartilage-tocartilage contact is the main contact pattern up to a knee flexion angle of $140^{\circ}$, at which the cartilage-tomeniscus contact begins to increase. Therefore, the reliability of CT-based CP is presumed to be relatively high for knee flexion angles from $90^{\circ}$ to $140^{\circ}$. They also reported that the medial femoral condyle and tibia sandwiched the posterior horn of the medial meniscus at a knee flexion angle of $160^{\circ}$ and had lost 
cartilage-to-cartilage contact. The cartilage-to-meniscus contact increases in a knee flexion angle range from $140^{\circ}$ to $160^{\circ}$, so the reliability of CT-based CP may become low. Therefore, the reliability of CT-based $\mathrm{CP}$ in the present study was considered to be relatively high at all knee flexion angles, excluding around the maximum knee flexion angle during kneeling activity.

The following points can be considered limitations of this study. First, it was CT-based and did not consider cartilage or meniscal conditions. Therefore, there was a possibility that the point where the cartilage of the femur and the tibia actually contacted each other in vivo and the CP calculated as the geometric centre of the contact area in this analysis did not match completely. Second, kneeling action is usually performed with both legs, but it was performed with one leg in the present study. A handrail was used to perform the kneeling action, so that half of the body weight was applied to the examined knee, as is the case with usual kneeling with both legs. However, it is unclear how much load was actually applied and how much muscle tone was involved. Third, only one sequence, the flexion phase first, followed by the extension phase, was analysed. The analysed knee flexion angles ranged from $100^{\circ}$ to maximum flexion in this study. Thus, it is impossible to analyse the kinematics and CPs for the data including angles less than $100^{\circ}$, or in which the order between the flexion phase and the extension phase is reversed. Fourth, electromyography and ground reaction force plate measurements were not performed. Therefore, it is not possible to directly prove the effect of muscle contraction and joint contact pressure in the present kinematic and CP analyses. In the future, it will be necessary to develop methods such as evaluating muscle activity and/or ground reaction force at the same time and unify the time axis during image capture.

\section{Conclusions}

There was a difference in the rotational kinematics between the flexion phase and the extension phase in kneeling. Furthermore, a large amount of anterior translation of the medial CP and a small amount of anterior translation of the lateral $\mathrm{CP}$ occurred in the extension phase. These results suggest that the kinematic difference between the flexion and extension phases may have some effects on the meniscus and articular cartilage.

\section{Abbreviations}

CP: contact point; AP: antero-posterior; IE: internal-external; CT: computed tomography; MRI: magnetic resonance imaging; OA: osteoarthritis; $\mathrm{Cl}$ : confidence interval; maxflex: maximum flexion

\section{Declarations}

\section{Ethics approval and consent to participate}

This study was performed with the approval (No. 08070298-2) of the Clinical Research Ethics Committee of Nagasaki University Hospital. All subjects provided their consent to participate in this study. 


\section{Consent for publication}

Not applicable.

\section{Availability of data and materials}

The datasets used and/or analysed during the current study are available from the corresponding author on reasonable request.

\section{Competing interests}

Declarations of interest: none

\section{Funding}

This research did not receive any specific grant from funding agencies in the public, commercial, or not-forprofit sectors.

\section{Authors' contributions}

YN and AY conceived the study and wrote the manuscript as the first author and corresponding author, respectively. TM and KG provided the methodology of the study. TM and KK contributed to collecting the cases. HT and KG contributed to creating a 3D bone model. MO supervised the study. NO, KC, TM, and MT made meaningful suggestions. All authors read and approved the final manuscript.

\section{Acknowledgements}

The authors would like to thank all of the staff involved in clinical research at Nagasaki University and Hiroshima International University. The authors would especially like to thank Ms. Mai Takahira of the radiology staff of our hospital who gave us tremendous technical support, and Dr. Shuntaro Sato for his resourceful professional opinions on statistical analysis.

\section{References}

1. Coggon D, Croft P, Kellingray S, Barrett D, McLaren M, Cooper C. Occupational physical activities and osteoarthritis of the knee. Arthritis Rheum. 2000;43:1443-9. doi:10.1002/15290131(200007)43:7<1443::AID-ANR5>3.0.CO;2-1. 
2. Baker P, Reading I, Cooper C, Coggon D. Knee disorders in the general population and their relation to occupation. Occup Environ Med. 2003;60:794-7. doi:10.1136/oem.60.10.794.

3. Jensen LK, Rytter S, Marott JL, Bonde JP. Relationship between years in the trade and the development of radiographic knee osteoarthritis and MRI-detected meniscal tears and bursitis in floor layers. A crosssectional study of a historical cohort. BMJ Open. 2012;2:e001109. doi:10.1136/bmjopen-2012-001109.

4. Snoeker BA, Bakker EW, Kegel CA, Lucas C. Risk factors for meniscal tears: a systematic review including meta-analysis. J Orthop Sports Phys Ther. 2013;43:352-67. doi:10.2519/jospt.2013.4295.

5. Hefzy MS, Kelly BP, Cooke TD, al-Baddah AM, Harrison L. Knee kinematics in-vivo of kneeling in deep flexion examined by bi-planar radiographs. Biomed Sci Instrum. 1997;33:453-8.

6. Iwaki H, Pinskerova V, Freeman MA. Tibiofemoral movement 1: the shapes and relative movements of the femur and tibia in the unloaded cadaver knee. J Bone Joint Surg Br. 2000;82:1189-95. doi:10.1302/0301-620x.82b8.10717.

7. Hill PF, Vedi V, Williams A, Iwaki H, Pinskerova V, Freeman MA. Tibiofemoral movement 2: the loaded and unloaded living knee studied by MRI. J Bone Joint Surg Br. 2000;82:1196-8. doi:10.1302/0301620x.82b8.10716.

8. Nakagawa S, Kadoya Y, Todo S, Kobayashi A, Sakamoto H, Freeman MAR, et al. Tibiofemoral movement 3: full flexion in the living knee studied by MRI. J Bone Joint Surg Br. 2000;82b:1199-200. doi:10.1302/0301-620x.82b8.10718.

9. Pinskerova V, Samuelson KM, Stammers J, Maruthainar K, Sosna A, Freeman MAR. The knee in full flexion: an anatomical study. J Bone Joint Surg Br. 2009;91b:830-4. doi:10.1302/0301620x.91b6.22319.

10. Komistek RD, Scott RD, Dennis DA, Yasgur D, Anderson DT, Hajner ME. In vivo comparison of femorotibial contact positions for press-fit posterior stabilized and posterior cruciate-retaining total knee arthroplasties. J Arthroplasty. 2002;17:209-16. doi:10.1054/arth.2002.29329.

11. Kanekasu K, Banks SA, Honjo S, Nakata O, Kato H. Fluoroscopic analysis of knee arthroplasty kinematics during deep flexion kneeling. J Arthroplasty. 2004;19:998-1003. doi:10.1016/j.arth.2004.03.012.

12. Incavo SJ, Mullins ER, Coughlin KM, Banks S, Banks A, Beynnon BD. Tibiofemoral kinematic analysis of kneeling after total knee arthroplasty. J Arthroplasty. 2004;19:906-10. doi:10.1016/j.arth.2004.03.020.

13. Coughlin KM, Incavo SJ, Doohen RR, Gamada K, Banks S, Beynnon BD. Kneeling kinematics after total knee arthroplasty: anterior-posterior contact position of a standard and a high-flex tibial insert design. J Arthroplasty. 2007;22:160-5. doi:10.1016/j.arth.2006.05.023.

14. Tanaka A, Nakamura E, Okamoto N, Banks SA, Mizuta H. Three-dimensional kinematics during deepflexion kneeling in mobile-bearing total knee arthroplasty. Knee. 2011;18:412-6. doi:10.1016/j.knee.2010.08.006.

15. Murakami K, Hamai S, Okazaki K, Ikebe S, Nakahara H, Higaki H, et al. Kinematic analysis of stair climbing in rotating platform cruciate-retaining and posterior-stabilized mobile-bearing total knee arthroplasties. Arch Orthop Trauma Surg. 2017;137:701-11. doi:10.1007/s00402-017-2662-6. 
16. Leszko F, Hovinga KR, Lerner AL, Komistek RD, Mahfouz MR. In vivo normal knee kinematics: is ethnicity or gender an influencing factor? Clin Orthop Relat Res. 2011;469:95-106. doi:10.1007/s11999-010-1517-z.

17. Tanifuji O, Sato T, Kobayashi K, Mochizuki T, Koga Y, Yamagiwa H, et al. Three-dimensional in vivo motion analysis of normal knees using single-plane fluoroscopy. J Orthop Sci. 2011;16:710-8. doi:10.1007/s00776-011-0149-9.

18. Hamai S, Moro-oka TA, Dunbar NJ, Miura H, Iwamoto Y, Banks SA. In vivo healthy knee kinematics during dynamic full flexion. Biomed Res Int. 2013;2013:717546. doi:10.1155/2013/717546.

19. Galvin CR, Perriman DM, Newman PM, Lynch JT, Smith PN, Scarvell JM. Squatting, lunging and kneeling provided similar kinematic profiles in healthy knees-A systematic review and meta-analysis of the literature on deep knee flexion kinematics. Knee. 2018;25:514-30. doi:10.1016/j.knee.2018.04.015.

20. Moro-oka TA, Hamai S, Miura H, Shimoto T, Higaki H, Fregly BJ, et al. Dynamic activity dependence of in vivo normal knee kinematics. J Orthop Res. 2008;26:428-34. doi:10.1002/jor.20488.

21. Kono K, Tomita T, Futai K, Yamazaki T, Tanaka S, Yoshikawa H, et al. In vivo three-dimensional kinematics of normal knees during different high-flexion activities. Bone Joint J. 2018;100-B:50-5. doi:10.1302/0301-620X.100B1.BJJ-2017-0553.R2.

22. Scarvell JM, Hribar N, Galvin CR, Pickering MR, Perriman DM, Lynch JT, et al. Analysis of kneeling by medical imaging shows the femur moves back to the posterior rim of the tibial plateau, prompting review of the concave-convex rule. Phys Ther. 2019;99:311-8. doi:10.1093/ptj/pzy144.

23. Galvin CR, Perriman DM, Lynch JT, Pickering MR, Newman P, Smith PN, et al. Age has a minimal effect on knee kinematics: a cross-sectional 3D/2D image-registration study of kneeling. Knee. 2019;26:9881002. doi:10.1016/j.knee.2019.07.012.

24. Dennis DA, Mahfouz MR, Komistek RD, Hoff W. In vivo determination of normal and anterior cruciate ligament-deficient knee kinematics. J Biomech. 2005;38:241-53. doi:10.1016/j.jbiomech.2004.02.042.

25. Grood ES, Suntay WJ. A joint coordinate system for the clinical description of three-dimensional motions: application to the knee. J Biomech Eng. 1983;105:136-44. doi:10.1115/1.3138397.

26. Banks SA, Hodge WA. Accurate measurement of three-dimensional knee replacement kinematics using single-plane fluoroscopy. IEEE Trans Biomed Eng. 1996;43:638-49. doi:10.1109/10.495283.

27. Fregly BJ, Rahman HA, Banks SA. Theoretical accuracy of model-based shape matching for measuring natural knee kinematics with single-plane fluoroscopy. J Biomech Eng. 2005;127:692-9. doi:10.1115/1.1933949.

28. Moro-oka TA, Hamai S, Miura H, Shimoto T, Higaki H, Fregly BJ, et al. Can magnetic resonance imagingderived bone models be used for accurate motion measurement with single-plane three-dimensional shape registration? J Orthop Res. 2007;25:867-72. doi:10.1002/jor.20355.

29. Komistek RD, Dennis DA, Mahfouz M. In vivo fluoroscopic analysis of the normal human knee. Clin Orthop Relat Res. 2003;410:69-81. doi:10.1097/01.blo.0000062384.79828.3b.

30. Miyaji T, Gamada K, Kidera K, Ikuta F, Yoneta K, Shindo H, et al. In vivo kinematics of the anterior cruciate ligament deficient knee during wide-based squat using a 2D/3D registration technique. J Sport 
Sci Med. 2012;11:695-702.

31. Kidera K, Yonekura A, Miyaji T, Nakazoe Y, Gamada K, Yoneta K, et al. Double-bundle anterior cruciate ligament reconstruction improves tibial rotational instability: analysis of squatting motion using a 2D/3D registration technique. J Orthop Surg Res. 2018;13:111. doi:10.1186/s13018-018-0825-y.

32. Nagura T, Dyrby CO, Alexander EJ, Andriacchi TP. Mechanical loads at the knee joint during deep flexion. J Orthop Res. 2002;20:881-6. doi:Pii S0736-0266(01)00178-4.

33. Nagura T, Otani T, Suda Y, Matsumoto H, Toyama Y. Is high flexion following total knee arthroplasty safe?: evaluation of knee joint loads in the patients during maximal flexion. J Arthroplasty. 2005;20:647-51. doi:10.1016/j.arth.2004.07.011.

34. Nagura T, Matsumoto H, Kiriyama Y, Chaudhari A, Andriacchi TP. Tibiofemoral joint contact force in deep knee flexion and its consideration in knee osteoarthritis and joint replacement. J Appl Biomech. 2006;22:305-13. doi:10.1123/jab.22.4.305.

35. Thompson WO, Thaete FL, Fu FH, Dye SF. Tibial meniscal dynamics using three-dimensional reconstruction of magnetic resonance images. Am J Sports Med. 1991;19:210-5. doi:10.1177/036354659101900302. discussion 215-6.

36. Fox AJ, Bedi A, Rodeo SA. The basic science of human knee menisci: structure, composition, and function. Sports Health. 2012;4:340-51. doi:10.1177/1941738111429419.

37. Kwak SD, Ahmad CS, Gardner TR, Grelsamer RP, Henry JH, Blankevoort L, et al. Hamstrings and iliotibial band forces affect knee kinematics and contact pattern. J Orthop Res. 2000;18:101-8. doi:10.1002/jor.1100180115.

38. MacWilliams BA, Wilson DR, Desjardins JD, Romero J, Chao EY. Hamstrings cocontraction reduces internal rotation, anterior translation, and anterior cruciate ligament load in weight-bearing flexion. $J$ Orthop Res. 1999;17:817-22. doi:10.1002/jor.1100170605.

39. Victor J, Labey L, Wong P, Innocenti B, Bellemans J. The influence of muscle load on tibiofemoral knee kinematics. J Orthop Res. 2010;28:419-28. doi:10.1002/jor.21019.

40. Li G, Park SE, DeFrate LE, Schutzer ME, Ji L, Gill TJ, et al. The cartilage thickness distribution in the tibiofemoral joint and its correlation with cartilage-to-cartilage contact. Clin Biomech (Bristol Avon). 2005;20:736-44. doi:10.1016/j.clinbiomech.2005.04.001.

41. Liu F, Kozanek M, Hosseini A, Van de Velde SK, Gill TJ, Rubash HE, et al. In vivo tibiofemoral cartilage deformation during the stance phase of gait. J Biomech. 2010;43:658-65. doi:10.1016/j.jbiomech.2009.10.028.

42. Qi W, Hosseini A, Tsai TY, Li JS, Rubash HE, Li G. In vivo kinematics of the knee during weight bearing high flexion. J Biomech. 2013;46:1576-82. doi:10.1016/j.jbiomech.2013.03.014.

43. Yin P, Li JS, Kernkamp WA, Tsai TY, Baek SH, Hosseini A, et al. Analysis of in-vivo articular cartilage contact surface of the knee during a step-up motion. Clin Biomech (Bristol Avon). 2017;49:101-6. doi:10.1016/j.clinbiomech.2017.09.005.

44. DeFrate LE, Sun H, Gill TJ, Rubash HE, Li G. In vivo tibiofemoral contact analysis using 3D MRI-based knee models. J Biomech. 2004;37:1499-504. doi:10.1016/j.jbiomech.2004.01.012. 
45. Behnam AJ, Herzka DA, Sheehan FT. Assessing the accuracy and precision of musculoskeletal motion tracking using cine-PC MRI on a 3.0T platform. J Biomech. 2011;44:193-7.

doi:10.1016/j.jbiomech.2010.08.029.

46. Borotikar BS, Sheehan FT. In vivo patellofemoral contact mechanics during active extension using a novel dynamic MRI-based methodology. Osteoarthritis Cartilage. 2013;21:1886-94. doi:10.1016/j.joca.2013.08.023.

47. Tanaka Y, Nakamura S, Kuriyama S, Ito H, Furu M, Komistek RD, et al. How exactly can computer simulation predict the kinematics and contact status after TKA? Examination in individualized models. Clin Biomech (Bristol Avon). 2016;39:65-70. doi:10.1016/j.clinbiomech.2016.09.006.

48. Matsuda S. CORR Insights(R): femoral component external rotation affects knee biomechanics: a computational model of posterior-stabilized TKA. Clin Orthop Relat Res. 2018;476:124-5. doi:10.1007/s11999.0000000000000093.

49. Zumbrunn T, Duffy MP, Rubash HE, Malchau H, Muratoglu OK, Varadarajan KM. ACL substitution may improve kinematics of PCL-retaining total knee arthroplasty. Knee Surg Sports Traumatol Arthrosc. 2018;26:1445-54. doi:10.1007/s00167-016-4372-y.

50. Wang Y, Fan Y, Zhang M. Comparison of stress on knee cartilage during kneeling and standing using finite element models. Med Eng Phys. 2014;36:439-47. doi:10.1016/j.medengphy.2014.01.004.

51. Peters AE, Akhtar R, Comerford EJ, Bates KT. Tissue material properties and computational modelling of the human tibiofemoral joint: a critical review. PeerJ. 2018;6:e4298. doi:10.7717/peerj.4298.

\section{Tables}

Table 1

Femoral posterior translation relative to the tibia 


\begin{tabular}{|c|c|c|c|c|c|c|c|c|}
\hline \multirow{2}{*}{$\begin{array}{l}\text { Knee } \\
\text { flexion } \\
\text { angle } \\
\left({ }^{\circ}\right)\end{array}$} & \multicolumn{4}{|c|}{ Flexion phase } & \multicolumn{3}{|c|}{ Extension phase } & \multirow[t]{2}{*}{$P$ value } \\
\hline & $\begin{array}{l}\mathrm{n} \\
\text { (knees) }\end{array}$ & $\begin{array}{l}\text { Posterior } \\
\text { translation } \\
(\mathrm{mm})\end{array}$ & (SD) & $\begin{array}{l}\text { Difference } \\
\text { from } \\
100^{\circ}\end{array}$ & $\begin{array}{l}\text { Posterior } \\
\text { translation } \\
(\mathrm{mm})\end{array}$ & (SD) & $\begin{array}{l}\text { Difference } \\
\text { from } \\
\text { maxflex }\end{array}$ & \\
\hline 100 & 11 & -5.6 & (3.2) & 0 & -4.5 & (3.0) & -36.4 & $0.002^{\star \star *}$ \\
\hline 105 & 13 & -3.7 & (3.1) & 1.9 & -2.7 & (3.2) & -34.6 & $0.002^{* \star}$ \\
\hline 110 & 14 & -1.5 & (3.1) & 4.1 & -0.5 & (3.5) & -32.4 & $0.002^{\star \star *}$ \\
\hline 115 & 15 & 1.2 & (3.7) & 6.8 & 2.1 & (4.3) & -29.8 & $0.010^{\star}$ \\
\hline 120 & 15 & 3.6 & (3.8) & 9.2 & 4.3 & (4.6) & -27.6 & $0.039 *$ \\
\hline 125 & 15 & 6.2 & $(4.1)$ & 11.8 & 6.6 & (4.7) & -25.3 & 0.18 \\
\hline 130 & 15 & 8.9 & $(4.2)$ & 14.5 & 9.1 & (4.6) & -22.8 & 0.36 \\
\hline 135 & 15 & 11.7 & $(4.2)$ & 17.3 & 11.9 & (4.5) & -20.1 & 0.41 \\
\hline 140 & 15 & 14.8 & $(4.1)$ & 20.4 & 14.9 & (4.4) & -17.0 & 0.38 \\
\hline 145 & 15 & 18.2 & $(4.1)$ & 23.8 & 18.4 & (4.3) & -13.6 & 0.46 \\
\hline 150 & 15 & 22.1 & $(4.2)$ & 27.7 & 22.2 & (4.3) & -9.7 & 0.68 \\
\hline 155 & 12 & 26.2 & $(4.7)$ & 31.8 & 26.1 & (4.6) & -5.8 & 0.72 \\
\hline Maxflex & 12 & 31.9 & (5.5) & 37.5 & 31.9 & (5.5) & 0 & - \\
\hline
\end{tabular}

Paired $t$-test; $*, \mathrm{P}<0.05 * *, \mathrm{P}<0.01$

SD: standard deviation; maxflex: maximum flexion

Table 2

Femoral external rotation relative to the tibia 


\begin{tabular}{|c|c|c|c|c|c|c|c|c|}
\hline \multirow{2}{*}{$\begin{array}{l}\text { Knee } \\
\text { flexion } \\
\text { angle } \\
\left({ }^{\circ}\right)\end{array}$} & \multirow[b]{2}{*}{$\begin{array}{l}\mathrm{n} \\
\text { (knees) }\end{array}$} & \multicolumn{3}{|c|}{ Flexion phase } & \multicolumn{3}{|c|}{ Extension phase } & \multirow[t]{2}{*}{$P$ value } \\
\hline & & $\begin{array}{l}\text { Femoral } \\
\text { external } \\
\text { rotation }\left({ }^{\circ}\right)\end{array}$ & (SD) & $\begin{array}{l}\text { Difference } \\
\text { from } \\
100^{\circ}\end{array}$ & $\begin{array}{l}\text { Femoral } \\
\text { external } \\
\text { rotation }\left({ }^{\circ}\right)\end{array}$ & (SD) & $\begin{array}{l}\text { Difference } \\
\text { from } \\
\text { maxflex }\end{array}$ & \\
\hline 100 & 11 & -0.6 & (5.0) & 0 & 11.8 & $(6.7)$ & -7.4 & $<0.001^{\star *}$ \\
\hline 105 & 13 & 1.0 & (6.8) & 1.5 & 13.8 & (6.5) & -5.4 & $<0.001^{\star *}$ \\
\hline 110 & 14 & 2.4 & (7.3) & 3.0 & 15.2 & $(6.2)$ & -4.0 & $<0.001^{\star \star}$ \\
\hline 115 & 15 & 2.8 & (7.5) & 3.3 & 16.9 & $(6.4)$ & -2.3 & $<0.001^{\star *}$ \\
\hline 130 & 15 & 4.2 & (7.7) & 4.8 & 18.1 & (6.4) & -1.1 & $<0.001^{\star *}$ \\
\hline 125 & 15 & 5.8 & (7.4) & 6.4 & 19.0 & (6.3) & -0.2 & $<0.001^{\star *}$ \\
\hline 130 & 15 & 7.7 & (6.7) & 8.3 & 19.6 & (6.3) & 0.4 & $<0.001^{\star *}$ \\
\hline 135 & 15 & 10.1 & (5.8) & 10.6 & 20.0 & $(6.4)$ & 0.8 & $<0.001^{\star *}$ \\
\hline 140 & 15 & 12.5 & $(4.9)$ & 13.1 & 20.1 & (6.6) & 0.9 & $<0.001^{* *}$ \\
\hline 145 & 15 & 14.9 & $(4.6)$ & 15.5 & 20.4 & $(6.7)$ & 1.2 & $0.001^{\star \star}$ \\
\hline 150 & 15 & 16.6 & $(4.9)$ & 17.1 & 20.5 & $(6.5)$ & 1.3 & $0.004^{\star \star}$ \\
\hline 155 & 12 & 18.5 & (5.2) & 19.1 & 22.3 & $(5.4)$ & 3.1 & $0.013^{*}$ \\
\hline Maxflex & 12 & 19.2 & (5.0) & 19.8 & 19.2 & $(5.0)$ & 0 & - \\
\hline
\end{tabular}

Paired $t$-test; $*, \mathrm{P}<0.05 * *, \mathrm{P}<0.01$

SD: standard deviation; maxflex: maximum flexion

Table 3

Anterior translation of the medial CP 


\begin{tabular}{|c|c|c|c|c|c|c|c|c|}
\hline \multirow{2}{*}{$\begin{array}{l}\text { Knee } \\
\text { flexion } \\
\text { angle } \\
\left({ }^{\circ}\right)\end{array}$} & \multirow[b]{2}{*}{$\begin{array}{l}\mathrm{n} \\
\text { (knees) }\end{array}$} & \multicolumn{3}{|c|}{ Flexion phase } & \multicolumn{3}{|c|}{ Extension phase } & \multirow[t]{2}{*}{$P$ value } \\
\hline & & $\begin{array}{l}\text { Anterior } \\
\text { translation } \\
(\mathrm{mm})\end{array}$ & (SD) & $\begin{array}{l}\text { Difference } \\
\text { from } \\
140^{\circ}\end{array}$ & $\begin{array}{l}\text { Anterior } \\
\text { translation } \\
(\mathrm{mm})\end{array}$ & (SD) & $\begin{array}{l}\text { Difference } \\
\text { from } \\
125^{\circ}\end{array}$ & \\
\hline 100 & 11 & -2.7 & (3.4) & -3.8 & 2.5 & $(4.4)$ & -2.4 & $<0.001^{* *}$ \\
\hline 105 & 13 & -1.8 & (3.9) & -2.9 & 3.1 & $(4.0)$ & -1.8 & $<0.001^{\star *}$ \\
\hline 110 & 14 & -1.3 & $(4.1)$ & -2.4 & 3.7 & (3.7) & -1.2 & $<0.001^{\star *}$ \\
\hline 115 & 15 & -1.2 & $(4.1)$ & -2.3 & 4.3 & (3.5) & -0.6 & $<0.001^{\star *}$ \\
\hline 120 & 15 & -0.6 & $(4.3)$ & -1.7 & 4.7 & (3.5) & -0.2 & $<0.001^{\star *}$ \\
\hline 125 & 15 & -0.1 & $(4.1)$ & -1.2 & 4.9 & (3.5) & 0 & $<0.001^{\star *}$ \\
\hline 130 & 15 & 0.5 & (3.8) & -0.6 & 4.7 & (3.4) & -0.2 & $<0.001^{\star *}$ \\
\hline 135 & 15 & 1.0 & (3.7) & -0.1 & 4.1 & (3.1) & -0.8 & $<0.001^{\star *}$ \\
\hline 140 & 15 & 1.1 & (3.5) & 0 & 3.0 & $(2.9)$ & -1.9 & $0.031^{\star}$ \\
\hline 145 & 15 & 0.5 & (3.0) & -1.6 & 1.5 & $(2.9)$ & -3.4 & 0.23 \\
\hline 150 & 15 & -0.9 & $(2.9)$ & -2.0 & -0.4 & $(3.1)$ & -5.3 & 0.44 \\
\hline 155 & 12 & -2.6 & $(2.6)$ & -3.7 & -1.9 & $(2.7)$ & -6.8 & 0.28 \\
\hline Maxflex & 12 & -6.1 & $(2.6)$ & -7.2 & -6.1 & $(2.6)$ & -11.0 & - \\
\hline
\end{tabular}

Paired $t$-test; $*, \mathrm{P}<0.05 * *, \mathrm{P}<0.01$

CP: contact point; SD: standard deviation; maxflex: maximum flexion

Table 4

Anterior translation of the lateral CP 


\begin{tabular}{|c|c|c|c|c|c|c|c|c|}
\hline \multirow{2}{*}{$\begin{array}{l}\text { Knee } \\
\text { flexion } \\
\text { angle } \\
\left({ }^{\circ}\right)\end{array}$} & \multirow[b]{2}{*}{$\begin{array}{l}\mathrm{n} \\
\text { (knees) }\end{array}$} & \multicolumn{3}{|c|}{ Flexion phase } & \multicolumn{3}{|c|}{ Extension phase } & \multirow[t]{2}{*}{$P$ value } \\
\hline & & $\begin{array}{l}\text { Anterior } \\
\text { translation } \\
(\mathrm{mm})\end{array}$ & (SD) & $\begin{array}{l}\text { Difference } \\
\text { from } \\
100^{\circ}\end{array}$ & $\begin{array}{l}\text { Anterior } \\
\text { translation } \\
(\mathrm{mm})\end{array}$ & (SD) & $\begin{array}{l}\text { Difference } \\
\text { from } \\
\text { maxflex }\end{array}$ & \\
\hline 100 & 11 & -0.6 & (3.3) & 0 & -5.0 & (2.6) & 9.8 & $<0.001^{* *}$ \\
\hline 105 & 13 & -1.3 & (3.5) & -0.7 & -5.4 & (2.7) & 9.4 & $<0.001^{\text {** }}$ \\
\hline 110 & 14 & -2.0 & (3.4) & -1.4 & -6.3 & (3.0) & 8.5 & $<0.001^{\text {** }}$ \\
\hline 115 & 15 & -2.6 & $(3.0)$ & -2.0 & -7.0 & (3.2) & 7.8 & $<0.001^{\text {** }}$ \\
\hline 120 & 15 & -3.5 & $(2.7)$ & -2.9 & -7.5 & (3.1) & 7.3 & $<0.001^{* *}$ \\
\hline 125 & 15 & -4.6 & $(2.4)$ & -4.0 & -8.1 & (2.8) & 6.7 & $<0.001^{\text {** }}$ \\
\hline 130 & 15 & -5.8 & $(2.3)$ & -5.2 & -8.9 & (2.7) & 5.9 & $<0.001^{* *}$ \\
\hline 135 & 15 & -7.0 & $(2.5)$ & -6.4 & -9.5 & (2.4) & 5.3 & $<0.001^{\text {** }}$ \\
\hline 140 & 15 & -8.2 & $(2.6)$ & -7.6 & -10.0 & (2.1) & 4.8 & $0.003^{\star \star}$ \\
\hline 145 & 15 & -9.4 & $(2.5)$ & -8.8 & -11.0 & (2.1) & 3.8 & $0.002^{\star \star}$ \\
\hline 150 & 15 & -10.9 & $(2.4)$ & -10.3 & -12.1 & $(2.2)$ & 2.7 & $0.003^{\star \star}$ \\
\hline 155 & 12 & -12.3 & $(2.4)$ & -11.7 & -13.4 & (2.4) & 1.4 & $0.004^{\star \star}$ \\
\hline Maxflex & 12 & -14.8 & $(2.9)$ & -14.2 & -14.8 & (2.9) & 0 & - \\
\hline
\end{tabular}

Paired $t$-test; $*, \mathrm{P}<0.05 * *, \mathrm{P}<0.01$

CP: contact point; SD: standard deviation; maxflex: maximum flexion

Figures 

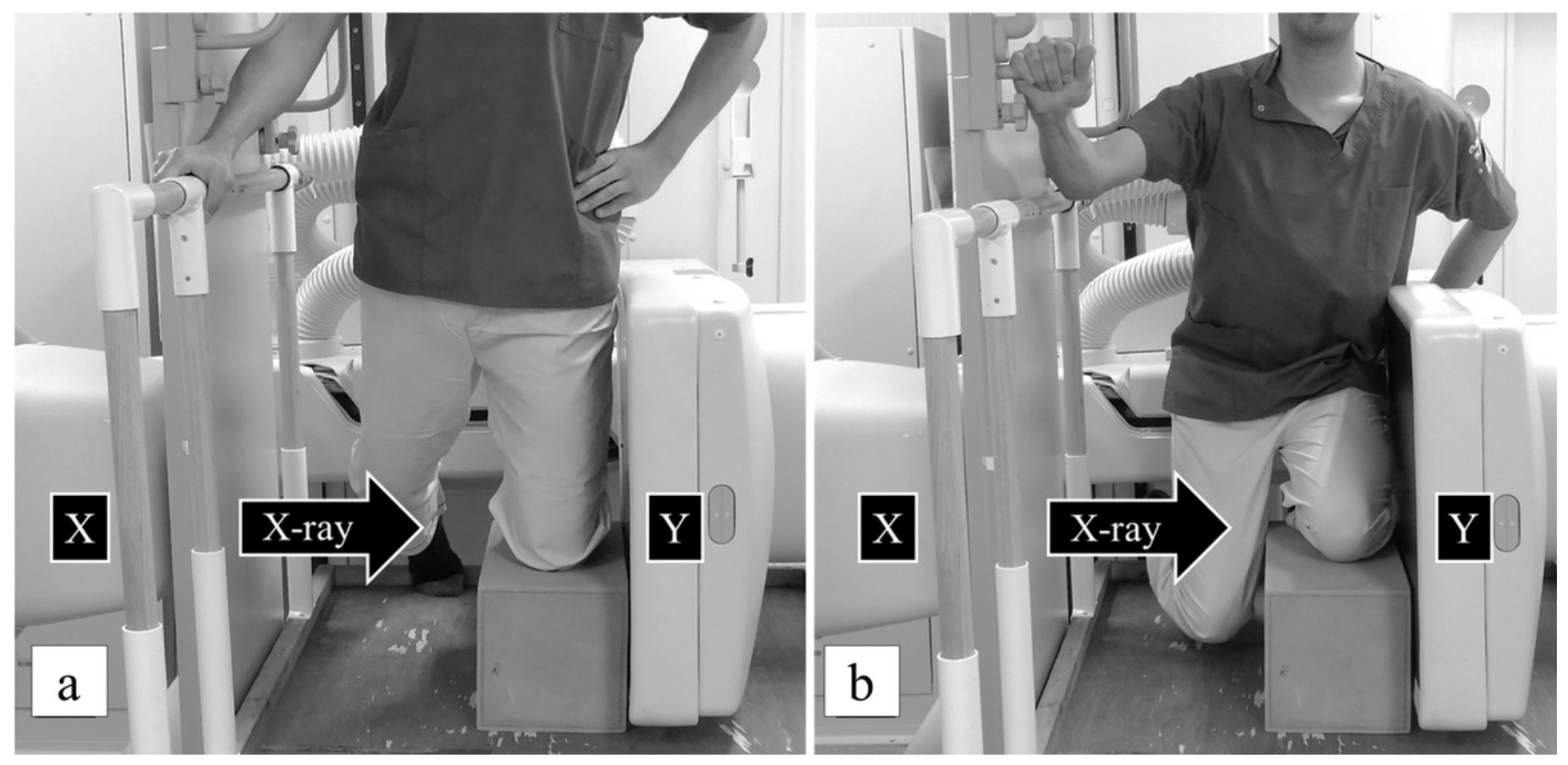

Figure 1

Kneeling action and lateral fluoroscopic imaging (a) represents the starting posture when the subject is kneeling with a knee flexion angle of $90^{\circ}$. (b) represents the posture when the subject flexes the knee to the maximum flexed angle from (a). X-rays are emitted from the radiation source $(X)$ toward the flat panel $(Y)$, and a series of actions are recorded.
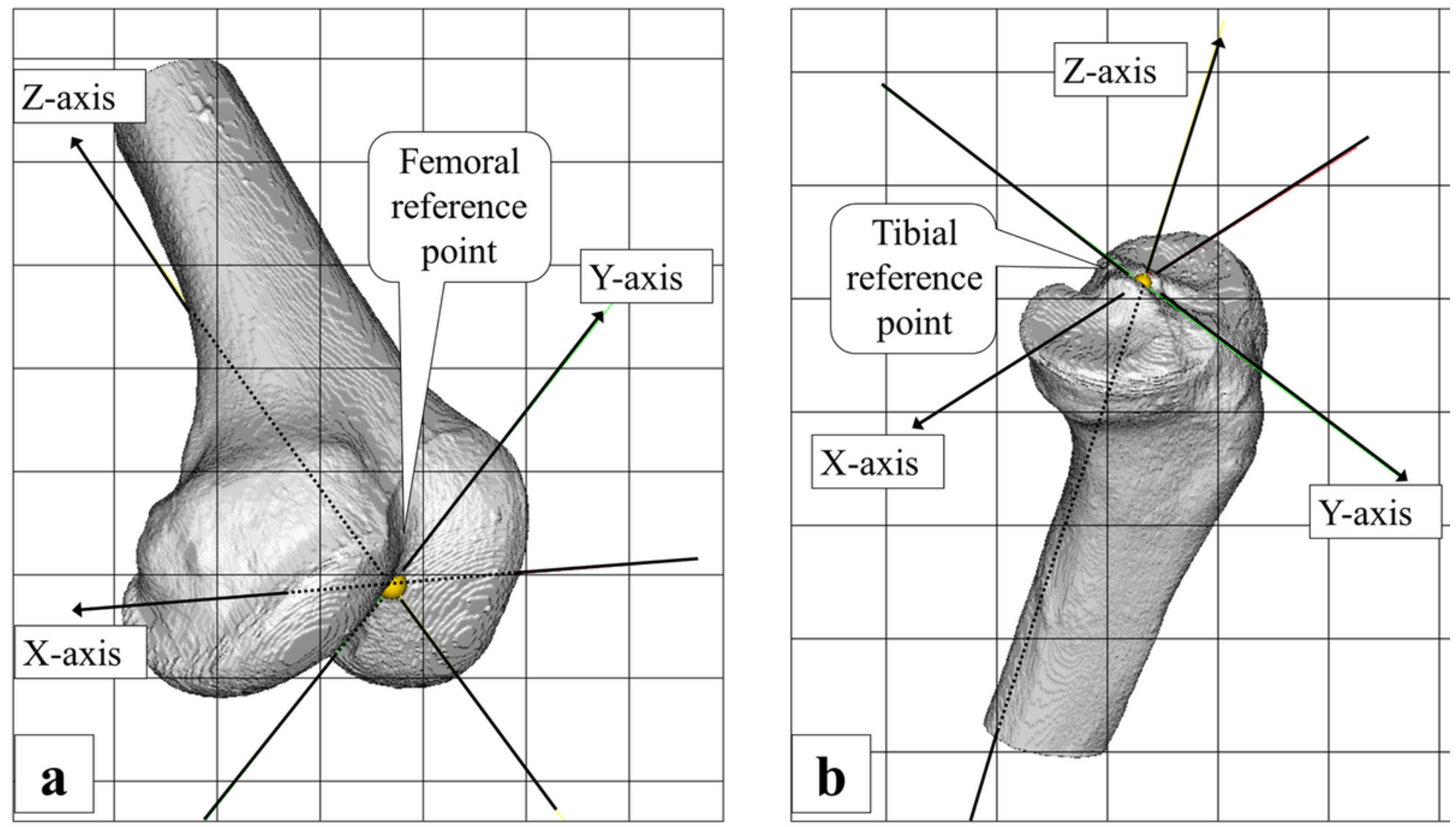


\section{Figure 2}

Femoral and tibial coordinate systems (a) shows the femoral coordinate system. The femoral reference point is located at the most distal point on the mid-plane of the intercondylar notch. The Z-axis points proximally and passes through the centre of the femoral head. The X-axis passes the femoral reference point and is parallel to the line connecting the most posterior points of the two femoral condyles. The $\mathrm{Y}$-axis is mutually perpendicular to the X-and Z-axes. (b) shows the tibial coordinate system. The tibial reference point is located at the centre of the apex of the medial-lateral intercondylar ridge and was the lowest point on the bone surface. The Z-axis points proximally and passes from the centre of the ankle joint and through the tibial reference point. The $X$-axis passes the tibial reference point and is parallel to the line connecting the midpoints of the medial and lateral tibial condyles. The $\mathrm{Y}$-axis is mutually perpendicular to the $\mathrm{X}$ - and Zaxes. 


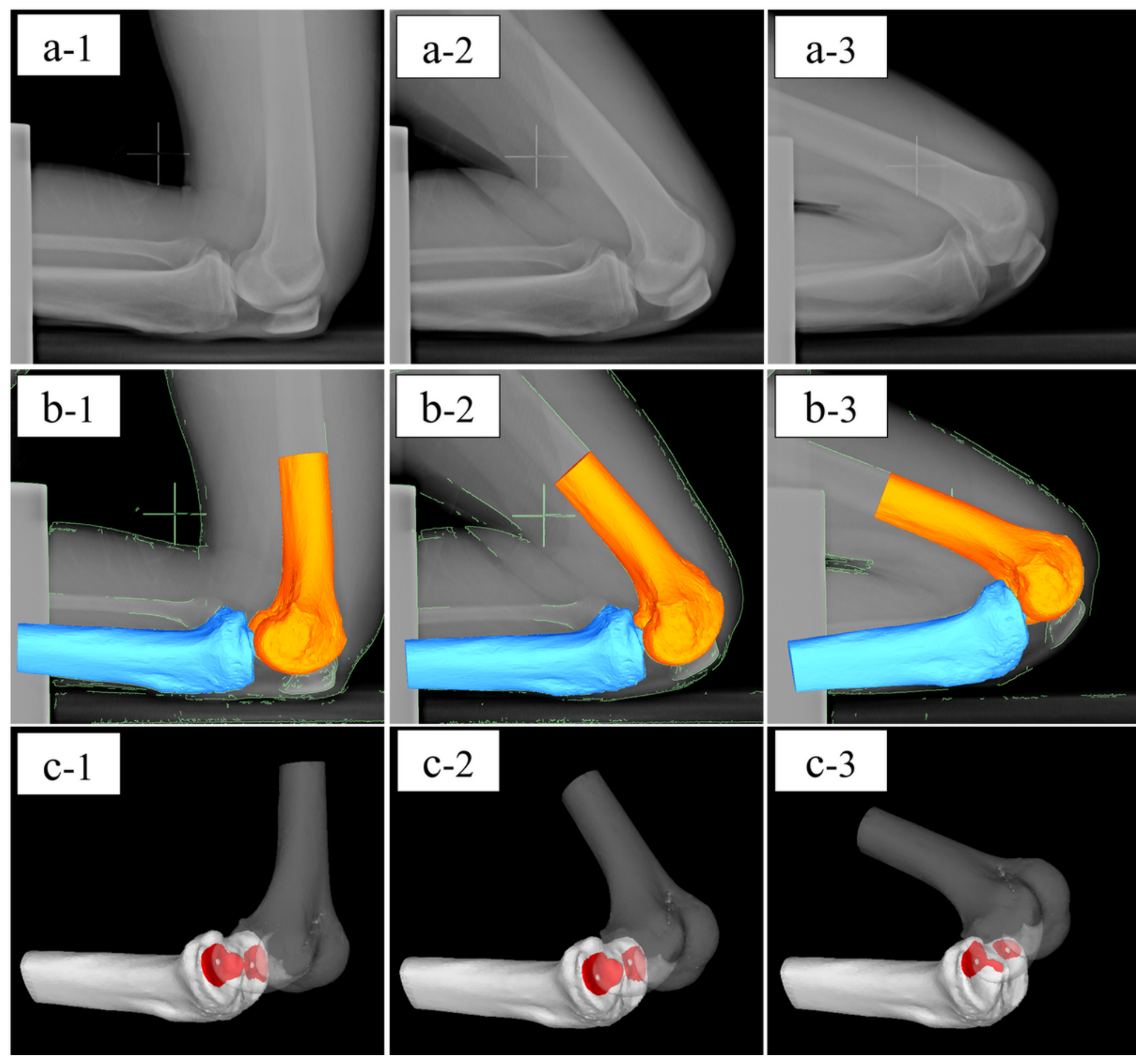

\section{Figure 3}

Kinematic and contact point analysis of the flexion phase (a) presents the lateral fluoroscopic images. (b) presents the bone models adjusted to match the lateral fluoroscopic images. The red area of (c) is the contact area, and the white point is the contact point that is the geometric centre of the contact area. The number 1 represents the starting position of kneeling activity, the number 2 represents the middle of flexion of the knee, and the number 3 represents the maximum flexion of the knee. 

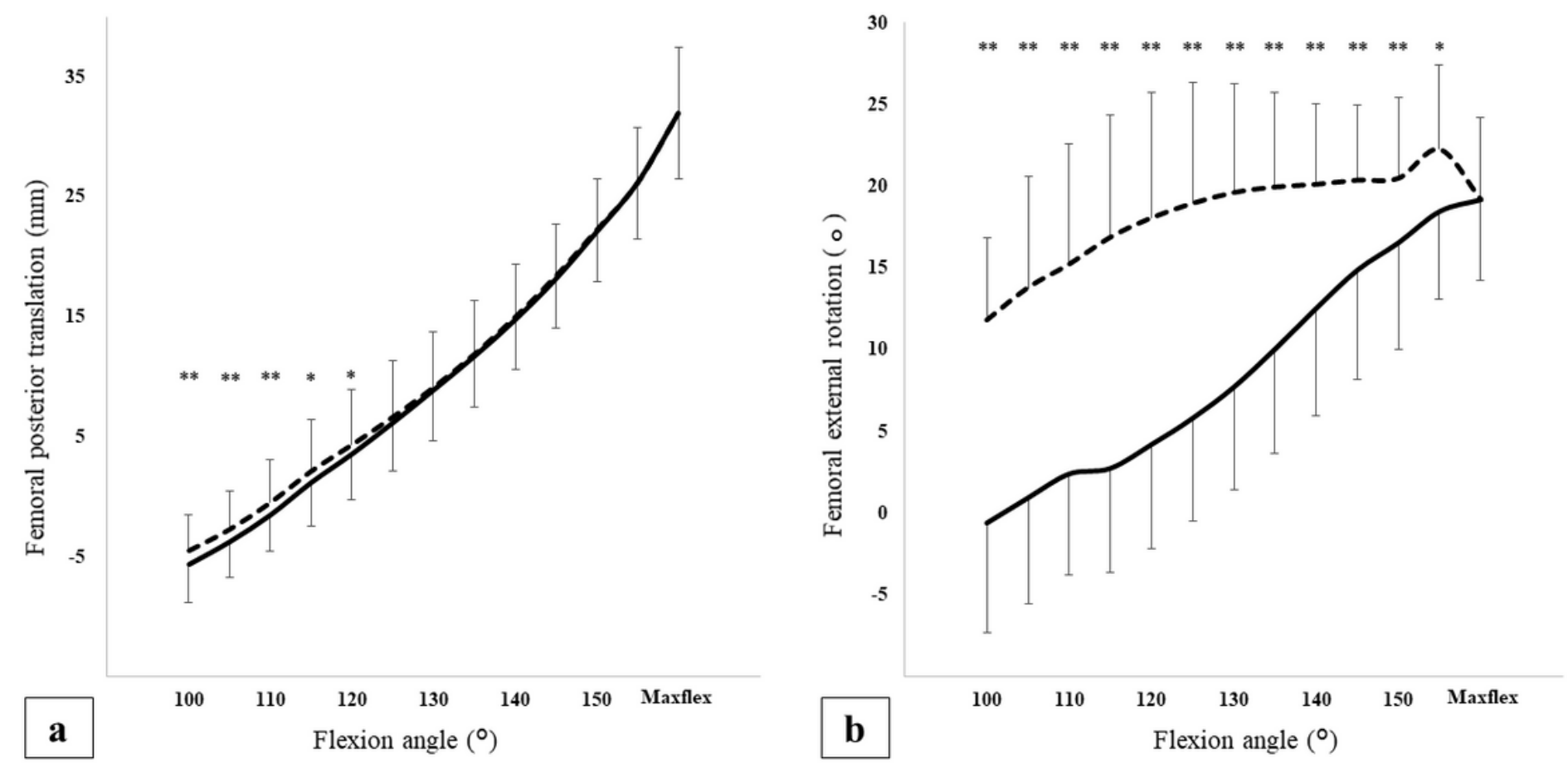

\section{Figure 4}

Kinematic data of the femur relative to the tibia (a) shows the femoral anterior-posterior translation (mm), plus indicates posterior translation, and minus indicates anterior translation. (b) shows femoral internalexternal rotation $\left({ }^{\circ}\right)$, plus indicates external rotation, and minus indicates internal rotation. The horizontal axis shows the knee flexion angle. The solid line represents the flexion phase, and the dashed line represents the extension phase. Paired t-test; $*, \mathrm{P}<0.05 * \star, \mathrm{P}<0.01$. 

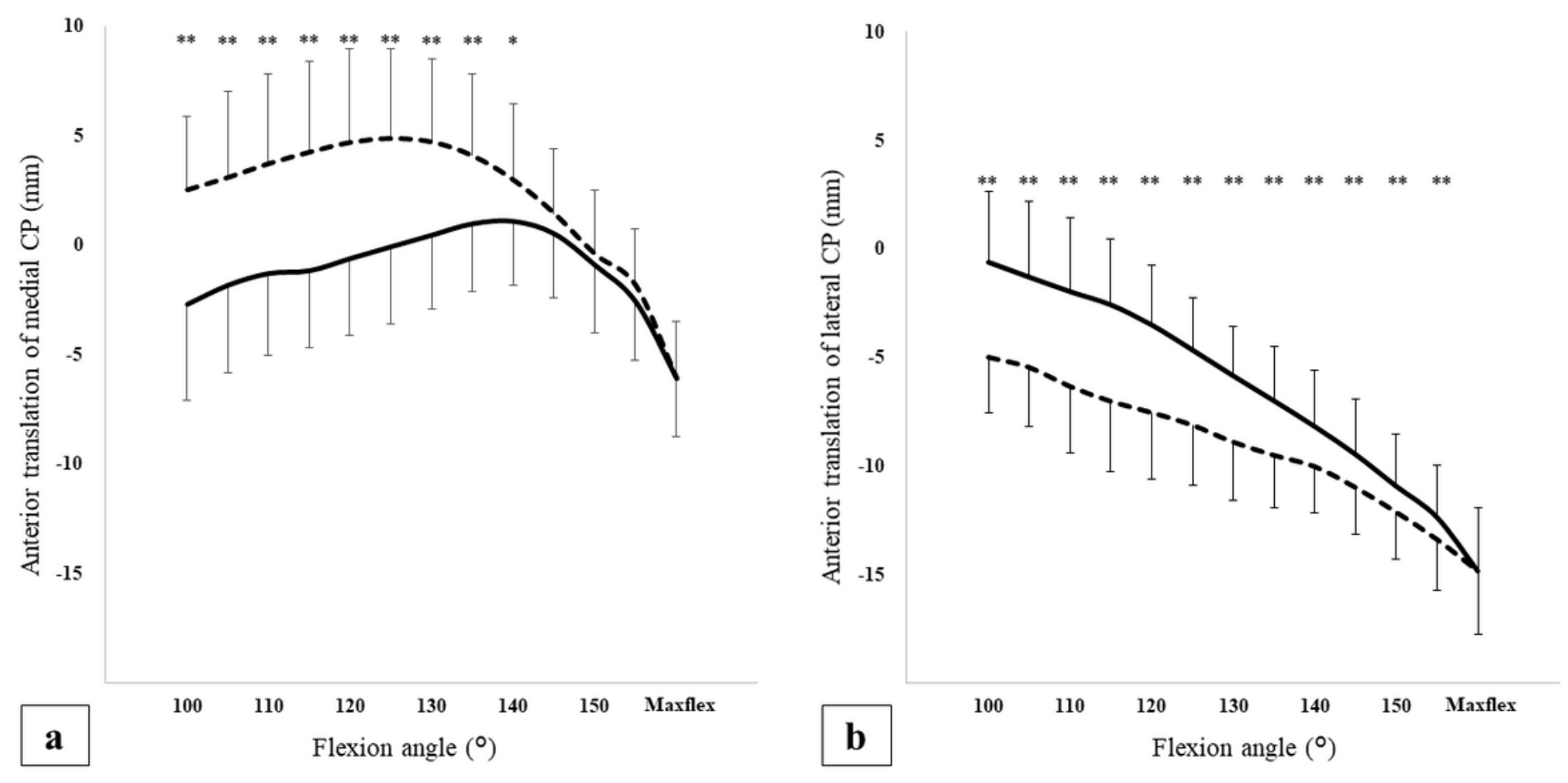

\section{Figure 5}

Antero-posterior translation of medial and lateral contact points (a) shows antero-posterior (AP) translation $(\mathrm{mm})$ of the medial contact point (CP). (b) shows AP translation $(\mathrm{mm})$ of the lateral CP. Plus indicates anterior translation of the $\mathrm{CP}$, and minus indicates posterior translation of the $\mathrm{CP}$. The horizontal axis shows the knee flexion angle. The solid line represents the flexion phase, and the dashed line represents the extension phase. Paired t-test; ${ }^{*}, \mathrm{P}<0.05 * \star, \mathrm{P}<0.01$. 